\title{
TP53 codon 72 polymorphism in susceptibility, overall survival, and adjuvant therapy response of gliomas
}

\author{
Vítor Lima-Ramos ${ }^{\mathrm{a}, 1}$, Luís Pacheco-Figueiredo ${ }^{\mathrm{a}, 1}$, Sandra Costa ${ }^{\mathrm{a}}$, Fernando Pardal ${ }^{\mathrm{b}}$, \\ Ana Silva ${ }^{\mathrm{b}}$, Júlia Amorimc, José Manuel Lopes ${ }^{\mathrm{d}, \mathrm{e}}$, Rui Manuel Reis ${ }^{\mathrm{a}, *}$ \\ ${ }^{\mathrm{a}}$ Life and Health Sciences Research Institute (ICVS), School of Health Sciences, University of Minho, \\ Campus de Gualtar, 4710-057 Braga, Braga, Portugal \\ ${ }^{\mathrm{b}}$ Department of Pathology, Hospital S. Marcos, Braga, Portugal \\ ${ }^{\mathrm{c}}$ Department of Oncology, Hospital S. Marcos, Braga, Portugal \\ ${ }^{\mathrm{d}}$ Institute of Molecular Pathology and Immunology-IPATIMUP, University of Porto, Porto, Portugal \\ ${ }^{\mathrm{e}}$ Hospital S. João, Medical Faculty, Department of Pathology, University of Porto, Porto, Portugal \\ Received 4 June 2007; accepted 31 August 2007
}

\begin{abstract}
TP53 is a key tumor suppressor gene that encodes a transcriptional factor involved in several cellular mechanisms, including growth arrest, DNA repair, and induction of apoptosis. In addition to TP53 gene mutations, a common polymorphism, Arg72Pro, has been involved in the carcinogenesis process. The Pro72 variant has been associated with a slower induction of apoptosis and may influence the risk of cancer development. The role of Arg72Pro polymorphism in glioma susceptibility is poorly characterized. With the objective of analyzing the role of the TP53 Arg72Pro polymorphism in glioma risk, overall survival, and patient therapy response in a Portuguese population, we conducted a retrospective case-control study, including 171 patients with gliomas and 526 cancer-free individuals. The Arg72Pro genotype was assessed by the polymerase chain reactionrestriction fragment length polymorphism technique. No statistically significant differences were observed in the genotypic and allelic frequencies between glioma and control groups, and no statistically significant differences were observed with stratification of gliomas into distinct histological subtypes: astrocytic $(n=115)$, glioblastoma $(n=75)$, and oligodendroglial $(n=54)$ tumors. No significant association was observed between TP53 Arg72Pro and patient overall survival, but Kaplan-Meier analysis of glioma patients harboring the Pro72 allele showed a significantly longer survival with adjuvant therapy. In this first assessment of the role of TP53 Arg72Pro polymorphism in a large series of Portuguese glioma tumors, no association was observed with glioma susceptibility or overall survival, except for patients submitted to adjuvant therapy. (C) 2008 Elsevier Inc. All rights reserved.
\end{abstract}

\section{Introduction}

Central nervous system tumors correspond to $<2 \%$ of adult tumors, but they are the second most common among pediatric tumors [1,2]. These tumors are an important cause of morbidity and mortality, being the first leading cause of cancer-related death in childhood and the fourth among middle aged-men [1,2]. In Portugal, the incidence of central nervous system tumors is similar to that in other European countries [3].

\footnotetext{
* Corresponding author. Tel.: +351-235-604825; fax: +351-253604820.

E-mail address: rreis@ecsaude.uminho.pt (R.M. Reis).

${ }^{1}$ These authors contributed equally to the present study.
}

Gliomas are the most common group of brain tumors; astrocytic tumors are the main histological type, followed by oligodendroglial and mixed oligoastrocytic tumors. Gliomas are classified into four grades of malignancy, according to the World Health Organization (WHO) classification [1]. Glioblastoma (WHO grade IV), the most malignant and frequent adult histological type, can be clinically and genetically subdivided into primary or de novo and secondary glioblastoma $[1,4,5]$. Primary glioblastomas correspond to $\sim 95 \%$ of the cases, evolve rapidly without any evidence of a less malignant precursor lesion, and are characterized by $E G F R$ amplification or overexpression $[1,4,5]$. Secondary glioblastomas develop more slowly, through progression of a less malignant lesion, and molecularly exhibit TP53 mutations and PDGFR overexpression [1,4,5]. With 
the exception of pilocytic astrocytomas (WHO grade I), prognosis of glioma patients remains poor, especially in glioblastomas, with a mean survival time of $\sim 1$ year and an overall 5-year survival rate of $<2 \%$ [1].

Little is known about the etiological factors of gliomas [6]. Several exogenous factors have been reported, such as the use of cell phones, exposure to high-tension wires, head trauma, and N-nitroso compounds, only ionizing radiation has been unequivocally implicated in glioma risk [6]. Genetically, only a small proportion of gliomas occur in a context of a familial cancer syndrome due to inherited high-penetrance mutations, such as $\mathrm{Li}-$ Fraumeni syndrome (TP53 germline mutation), neurofibromatosis 1 syndrome (NFI germline mutation), neurofibromatosis 2 syndrome (NF2 germline mutation), and Turcot syndrome (MLHI or PMS2 and APC germline mutation) [1]. The great majority of gliomas arise sporadically, and current evidence suggests that low-penetrance genetic polymorphisms can play a role in susceptibility to sporadic tumors [7]. Polymorphisms of genes involved in DNA repair, cell cycle control, carcinogen metabolism, or immune response have been associated with higher susceptibility to glioma development, but without consistent findings [7].

The TP53 tumor suppressor gene encodes a transcriptional factor, p53, which is involved in a diversity of cellular processes, including growth arrest, induction of apoptosis, DNA repair, and inhibition of angiogenesis [8]. The p53 protein is activated in response to various genotoxic and nongenotoxic stimulus, triggering the expression of several genes that affect cell cycle arrest (via the p21 pathway) and DNA repair (via the GADD45 pathway). If repair fails, apoptosis is triggered (via the bax pathway), hence, the denomination of p53 as the "genome guardian" [9]. Inactivation of TP53 by somatic mutations is a key molecular event, detected in $\sim 50 \%$ of all malignancies and in $\sim 40 \%$ of gliomas [10].

Several studies have focused on TP53 polymorphisms as predisposing factors for tumor development [11]. One such polymorphism is the TP53 Arg72Pro, located in exon 4 at codon 72 , involving a guanine to cytosine nucleotide exchange, which leads to nonconservative change of an arginine to proline. This single-nucleotide polymorphism is located in a proline-rich encoding region of TP53 gene, which is important for growth suppression and apoptotic function of p53 protein, indicating that Arg72 and Pro72 variants have distinct biochemical and biological activities [11]. Arg72 is significantly more efficient than Pro72 in apoptosis induction, and Pro72 individuals have been shown to be at higher risk of develop cancer [12-18]. In some epithelial cancers, the Pro72 variant was associated with a worse survival than $\operatorname{Arg} 72[15,19]$. On the other hand, Pro72 is shown to be a stronger inducer of transcription than Arg72 [12], and some studies suggest that Arg72 variant is more susceptible than Pro72 to degradation by human papillomavirus E6 protein [20].

Few reports have addressed the association of Arg72Pro polymorphism with susceptibility to glioma, and the results obtained are inconsistent [21-25]. Moreover, there are no reports concerning the association between this polymorphism and glioma patient outcome or adjuvant therapy response. Our objective was to determine whether TP53 Arg72Pro polymorphism represents a predisposition factor for glioma risk and to identify the impact on patient survival and therapeutic response in a Portuguese population.

\section{Materials and methods}

\subsection{Patient and control populations}

In this retrospective analysis, tumor samples were obtained from patients treated at Hospital S. João, Porto, and at Hospital S. Marcos, Braga, Portugal, as previously described [26]. The study of Arg72Pro polymorphisms included 171 patients with sporadic gliomas of distinct histological subtypes (Table 1) and 526 cancer-free individuals. The cancer-free control group was randomly selected from blood donors at Hospital S. Marcos, Bragal, and from Clínica Laboratorial and Dr. Edgar Botelho Moniz, Santo Tirso. All patients and control subjects were from northwestern Portugal and of European-origin ethnic background. The mean age of the patient population was 49.5 years; the mean age of the control group was 38.1 years. The distribution by sex of the patients was matched between patients (52.6\% male, $47.4 \%$ female) and the control group (50.2\% male, $49.8 \%$ female).

The procedures followed in the present study were in accordance with the institutional ethical standards. All samples enrolled in the present study were deidentified and unlinked from their donors.

\subsection{DNA preparation}

Tumor DNA was obtained from paraffin-embedded sections, as previously described [26]. (For the great majority of glioma patients, no peripheral blood DNA was available.) Briefly, paraffin was removed by incubation in

Table 1

Histological and clinical features of glioma patients

\begin{tabular}{lllll}
\hline & & & & \\
Tumor type & grade & $\begin{array}{l}\text { Cases, } \\
\text { no. }\end{array}$ & $\begin{array}{l}\text { Age, years, } \\
\text { mean } \pm \text { SD }\end{array}$ & $\begin{array}{l}\text { Male/ } \\
\text { female, } \\
n / n\end{array}$ \\
\hline Astrocytic & & & & \\
$\quad$ Pilocytic astrocytoma & I & 6 & $24.8 \pm 7.1$ & $2 / 4$ \\
$\quad$ Diffuse astrocytoma & II & 24 & $36.5 \pm 13.2$ & $9 / 15$ \\
$\quad \begin{array}{l}\text { Anaplastic astrocytoma } \\
\text { Glioblastoma }\end{array}$ & III & 4 & $38.8 \pm 12.9$ & $4 / 0$ \\
$\quad$ Gliosarcoma & IV & 75 & $57.2 \pm 12.3$ & $40 / 35$ \\
Oligodendroglial & IV & 6 & $60.5 \pm 10.3$ & $3 / 3$ \\
$\quad \begin{array}{l}\text { Oligodendroglioma } \\
\text { Anaplastic oligodendroglioma }\end{array}$ & II & 22 & $38.1 \pm 15.9$ & $12 / 10$ \\
Oligoastrocytic & & 32 & $53.3 \pm 11.2$ & $19 / 13$ \\
$\quad$ Oligoastrocytoma & II & 2 & $41.5 \pm 19.1$ & $1 / 1$ \\
TotaL & & 171 & $49.5 \pm 15.9$ & $90 / 81$ \\
\hline
\end{tabular}

${ }^{\text {a }}$ All are primary de novo glioblastomas. 
xylene, followed by ethanol washing, drying, and digestion in $100 \mu \mathrm{L}$ of lysis buffer $(500 \mathrm{mmol} / \mathrm{L}$ Tris- $\mathrm{HCl}, \mathrm{pH} 8.5$, and $1 \mathrm{mmol} / \mathrm{L}$ EDTA, $\mathrm{pH} 8.0$, containing proteinase $\mathrm{K}$ to a final concentration of $0.5 \mathrm{mg} / \mathrm{mL}$ ) at $55^{\circ} \mathrm{C}$ for 48 hours. After heat denaturation, DNA samples were stored at $-20^{\circ} \mathrm{C}$ for subsequent molecular analysis. DNA of the control population was extracted from peripheral blood leukocytes according to the proteinase $\mathrm{K}$-chloroformisopropanol protocol [27].

\subsection{TP53 Arg72Pro genotyping analysis}

Analysis of TP53 Arg72Pro polymorphism was performed by polymerase chain reaction-restriction fragment length polymorphism (PCR-RFLP). Briefly, amplification reaction was carried out in a total volume of $25 \mu \mathrm{L}$, consisting of $2 \mu \mathrm{L}$ of DNA solution, $1 \mathrm{U}$ Taq DNA polymerase (Bioron, Ludwigshafen, Germany), $1.5 \mathrm{mmol} / \mathrm{L} \mathrm{MgCl}_{2}$ (Bioron), 0.2 $\mathrm{mmol} / \mathrm{L}$ of each dNTP (Fermentas, Burlington, ON, Canada), $0.1 \mu \mathrm{mol} / \mathrm{L}$ of both sense and antisense primers, and $1 \times$ enzyme buffer (Bioron). PCR amplification was performed in an Primus 96 Plus thermal cycler (MWG Biotech, High Point, NC), with an initial denaturation step at $94^{\circ} \mathrm{C}$ for 5 minutes, then amplified for 38 cycles of denaturation at $94^{\circ} \mathrm{C}$ for 45 seconds, annealing at $55^{\circ} \mathrm{C}$ for 45 seconds, extension at $72^{\circ} \mathrm{C}$ for 45 seconds, and final extension step at $72^{\circ} \mathrm{C}$ for 10 minutes. Primer sequences were: $5^{\prime}$-CTGCCCTGGTA GGTTTTCTG-3' (reverse) and 5'-GAAGACCCAGGTCC AGATGA-3' (forward), leading to a 152-bp PCR product.

The PCR product was then analyzed by RFLP. he DNA PCR products were digested overnight at $37^{\circ} \mathrm{C}$ with Bsh1236I (Fermentas), according to the manufacturer's instructions. The results of enzymatic digestion were visualized in a 3\% agarose gel by electrophoresis. The results were the 152-bp fragment of uncut PCR product representing homozygotes proline, two fragments of 50 and $102 \mathrm{bp}$ representing homozygotes arginine, and three fragments of 50, 102 , and 152 bp representing heterozygotes for codon 72 .

\subsection{Statistical analysis}

Analysis of data was performed using the SPSS version 14.0 computer software (SPSS, Chicago, IL). Chi-square analysis was used to compare categorical variables. A 5\% level of significance was used in the analysis. The odds ratio (OR) and its $95 \%$ confidence interval (CI) were calculated to measure the association between TP53 Arg72Pro polymorphism and glioma risk. Logistic regression analysis was used to calculate the adjusted OR and $95 \%$ CI for the influence of TP53 genotypes in the risk of glioma, adjusted for age. Whenever appropriate, the observed number of each genotype was compared with that expected for a population in the Hardy-Weinberg equilibrium by using a goodness of fit $\chi^{2}$ test.

Survival and adjuvant treatment (radiotherapy and/or chemotherapy) data was available for 117 of the 171 patients. The probabilities of survival were calculated, and the medians and life-tables were computed using the product-limit estimate of Kaplan-Meier. The curves were examined by the log-rank test, a statistical test for equality of survival distributions. Survival duration was defined as the time between diagnosis and death or the time to the most recent clinical evaluation of the patient.

\section{Results}

The frequencies of the Arg/Arg, Arg/Pro, and Pro/Pro genotypes in the control group were $56.7 \%, 37.5 \%$ and $5.9 \%$, respectively, resulting in a Pro allele frequency of 0.25 . The distribution of these genotype frequencies was in agreement with those calculated from the HardyWeinberg equilibrium model for controls $(P=0.986)$.

The distribution of the three different TP53 codon 72 genotypes (Arg/Arg, Arg/Pro, and Pro/Pro) in both groups (cases and controls) is presented in Table 2. First, we compared the distribution of the TP53 Arg72Pro genotypes in glioma with the control group; no statistical difference was found $(P>0.05)$. Likewise, the distribution of the Pro allele variant between case and control groups was not statistically different $(P>0.05)$ (Table 2$)$.

We further stratified glioma cases by the histological subtypes astrocytic (grade I, II, III, and IV), glioblastoma (grade IV), and oligodendroglial (grade II and III) tumors and determined their genotype distribution. The genotype frequencies of the three histological groups were not statistically different from that of the control group $(P>0.05)$ (Table 2), and no statistical difference was found in the allelic distribution $(P>0.05)$ of these groups. Assessment of other stratification groups - diffusely infiltrating astrocytic tumors (grade II, III, IV), low-grade astrocytic tumors (grade I and II), and highgrade astrocytic tumors (grade III and IV) - revealed no significant differences (data not shown).

Kaplan-Meier curves were performed, to evaluate the possible association between the Arg72Pro polymorphism and overall patient survival. No statistical difference was observed $(P>0.05)$ for the gliomas $(n=117)$ for either 5 -year or 10-year analysis (Fig. 1). Likewise, no significant associations were observed for the glioblastoma and oligodendroglioma subtypes (data not shown).

We also assessed the role of the Arg72Pro polymorphism with patient response to adjuvant treatment (radiotherapy or chemotherapy or both; $n=42$ ). In the 5-year analysis, the median survival time in months of gliomas in patients with adjuvant therapy was $13 \pm 20.4$ SD for the Arg/Arg genotype, $24 \pm 33.7 \mathrm{SD}$ for the Arg/Pro genotype, and $57 \pm$ 30.2 SD for the Pro/Pro genotype. Kaplan-Meier curves showed a tendency of longer survival associated with patients exhibiting Pro/Pro genotype $(P=0.076)$ (data not shown) and a significantly longer survival in patients harboring the Pro allele (Arg/Pro + Pro/Pro, $P=0.027$ ) (Fig. 2). Upon histological stratification, only the oligodendroglioma 
Table 2

Frequency of TP53 Arg72Pro genotypes in glioma patients and healthy individuals

\begin{tabular}{|c|c|c|c|c|c|c|}
\hline \multirow[b]{2}{*}{ Genotype } & \multicolumn{2}{|c|}{ Group 1, controls } & \multicolumn{2}{|c|}{ Group 2, patients } & \multirow[b]{2}{*}{$P$ value } & \multirow[b]{2}{*}{ OR $(95 \% \mathrm{CI})$} \\
\hline & No. & $\%$ & No. & $\%$ & & \\
\hline \multicolumn{7}{|l|}{ Gliomas } \\
\hline Arg/Arg & 298 & 56.7 & 101 & 59.0 & Ref. & \\
\hline Arg/Pro & 197 & 37.5 & 56 & 32.7 & 0.355 & $0.84(0.58-1.22)$ \\
\hline \multirow[t]{3}{*}{ Pro/Pro } & 31 & 5.9 & 14 & 8.2 & 0.400 & $1.33(0.68-2.60)$ \\
\hline & & & & & $0.580^{\mathrm{a}}$ & $0.91(0.64-1.29)^{\mathrm{a}}$ \\
\hline & & & & & $0.289^{\mathrm{b}}$ & $1.42(0.74-2.74)^{\mathrm{b}}$ \\
\hline Arg allele & 793 & 75.4 & 258 & 75.0 & Ref. & \\
\hline Pro allele & 259 & 24.6 & 86 & 25.0 & 0.887 & $1.02(0.76-1.37)$ \\
\hline \multicolumn{7}{|l|}{ Astrocytomas $^{c}$} \\
\hline Arg/Arg & 298 & 56.7 & 70 & 60.9 & Ref. & \\
\hline Arg/Pro & 197 & 37.5 & 37 & 32.2 & 0.315 & $0.80(0.52-1.24)$ \\
\hline \multirow[t]{3}{*}{ Pro/Pro } & 31 & 5.9 & 8 & 6.9 & 0.822 & $1.10(0.48-2.49)$ \\
\hline & & & & & $0.408^{\mathrm{a}}$ & $0.84(0.56-1.27)^{\mathrm{a}}$ \\
\hline & & & & & $0.666^{\mathrm{b}}$ & $1.19(0.53-2.67)^{\mathrm{b}}$ \\
\hline Arg allele & 793 & 75.4 & 177 & 77.0 & Ref. & \\
\hline Pro allele & 259 & 24.6 & 53 & 23.0 & 0.614 & $0.92(0.64-1.30)$ \\
\hline \multicolumn{7}{|l|}{ Glioblastomas } \\
\hline Arg/Arg & 298 & 56.7 & 47 & 62.7 & Ref. & \\
\hline Arg/Pro & 197 & 37.5 & 24 & 32.0 & 0.333 & $0.77(0.46-1.30)$ \\
\hline \multirow[t]{3}{*}{ Pro/Pro } & 31 & 5.9 & 4 & 5.3 & 0.717 & $0.82(0.28-2.42)$ \\
\hline & & & & & $0.325^{\mathrm{a}}$ & $0.78(0.47-1.28)^{\mathrm{a}}$ \\
\hline & & & & & $0.846^{\mathrm{b}}$ & $0.90(0.31-2.62)^{\mathrm{b}}$ \\
\hline Arg allele & 793 & 75.4 & 118 & 78.7 & Ref. & \\
\hline Pro allele & 259 & 24.6 & 32 & 21.3 & 0.379 & $0.83(0.54-1.28)$ \\
\hline \multicolumn{7}{|c|}{ Oligodendrogliomas } \\
\hline Arg/Arg & 298 & 56.7 & 31 & 57.4 & Ref. & \\
\hline Arg/Pro & 197 & 37.5 & 18 & 33.3 & 0.676 & $0.88(0.48-1.61)$ \\
\hline \multirow[t]{3}{*}{ Pro/Pro } & 31 & 5.9 & 5 & 9.3 & 0.393 & $1.55(0.56-4.28)$ \\
\hline & & & & & $0.915^{\mathrm{a}}$ & $0.97(0.55-1.70)^{\mathrm{a}}$ \\
\hline & & & & & $0.329^{\mathrm{b}}$ & $1.63(0.61-4.38)^{b}$ \\
\hline Arg allele & 793 & 75.4 & 80 & 74.1 & Ref. & \\
\hline Pro allele & 259 & 24.6 & 28 & 25.9 & 0.765 & $1.07(0.66-1.72)$ \\
\hline
\end{tabular}

Abbreviations: CI, confidence interval; OR, odds ratio; Ref., reference value.

${ }^{\text {a }}$ Pro/Pro + Arg/Pro genotype frequencies vs. Arg/Arg genotype.

${ }^{\mathrm{b}}$ Pro/Pro genotype frequency vs. Arg/Arg + Arg/Pro genotypes.

c Types I, II, III, and IV in the WHO classification [1].

subgroup showed a similar longer survival associated with harboring the Pro allele $(P=0.044)$. No statistical difference was observed in the 10-year analysis (data not shown).

\section{Discussion}

Genetic polymorphisms are known to play a role on cancer susceptibility, and their role on glioma risk is starting to be evaluated [7]. In particular, polymorphisms involved in DNA repair enzymes (e.g., $P R K D C$, alias XRCC7; ERCC1, $E R C C 2$ ), growth factors (e.g., $E G F$ ), immune response (IL4 and IL13), and metabolism (e.g., GSTT1) have been associated with glioma susceptibility [7,26,28-31].

In the present study, we evaluated the role of Arg72Pro polymorphism of the TP53 gene in susceptibility to developing glioma in a Portuguese population. The results showed no significant difference in the genotypic and allelic frequencies between gliomas and controls, and no significant association was detected between the genotype and allele distributions and tumor histological type. These findings are in agreement with previous reports in gliomas from distinct geographic regions [21,22,24,32]. At variance with these results, Parhar et al. [23], reported a significant association between the Arg/Pro genotype and an increased risk for high-grade astrocytic tumors. These authors also found a significant difference in Arg/Pro genotype distribution between high-grade astrocytic tumors and nonastrocytic tumors, including oligodendroglial and oligoastrocytic tumors [23]. In the present study, we found no differences between these type of tumors. Notably, Malmer et al. [25] recently found that the Arg72Pro polymorphism alone had no impact on glioma risk, but in combination with two other single-nucleotide polymorphisms of TP53 gene (one at the promoter and the other in intron 6) there was an association of risk haplotypes and protective haplotypes in the TP53 gene for glioblastomas [25].

Several explanations can be offered for the discrepancies observed. (1) The populations analyzed were different. Beckman et al. [33] were the first to note a significant 


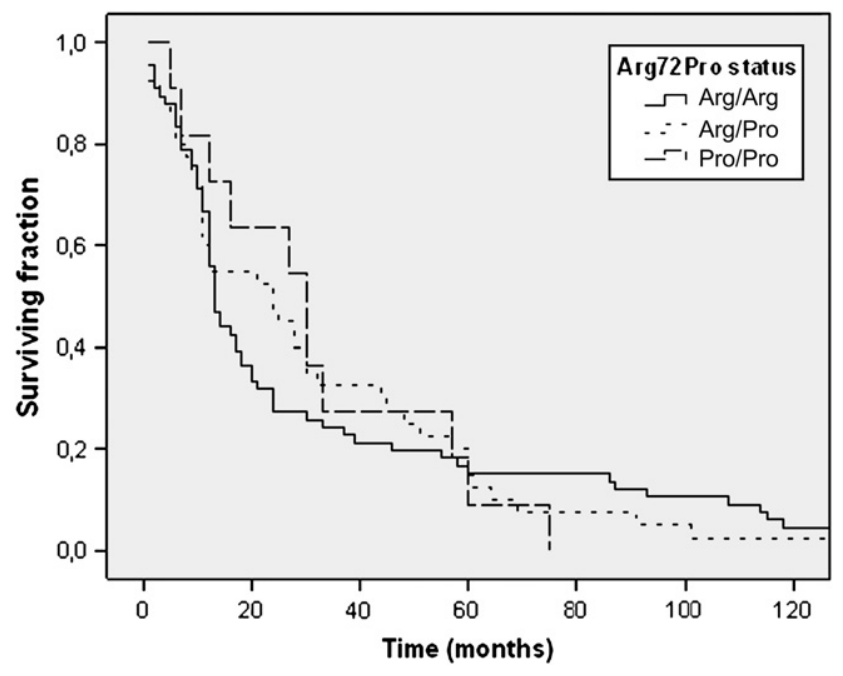

Fig. 1. Kaplan-Meier survival curves of glioma tumor patients $(n=117)$ as a function of TP53 codon 72 genotypes $(P=0.968)$.

difference in the allelic distribution of Arg72Pro variants among Nigerian and Swedish populations, and subsequent studies showed that latitude could explain different allelic population frequencies [34]. Siddique et al. [35] found a preferential expression of either Arg72 or Pro72 allele variants, depending on the ethnicity of the population. (2) The DNA source (peripheral blood lymphocyte or tumor tissue) used in the studies was different. If tumor tissue is used, as in our study, allele retention due to mutation or loss of heterozygosity cannot be excluded. Nonetheless, the present findings are not necessarily influenced significantly by the possible allele retention that may have occurred in few of our cases. (3) Tumor histological stratification

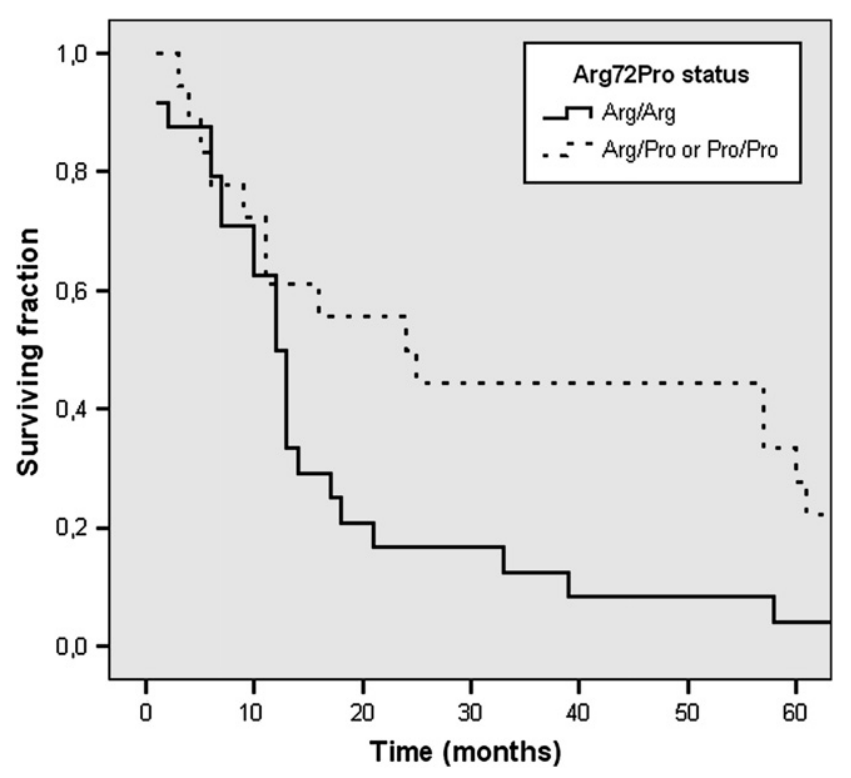

Fig. 2. Kaplan-Meier survival curves of glioma tumor patients treated with adjuvant therapy $(n=42)$ as a function of TP53 codon 72 genotypes $(P=0.027)$. among studies was not uniform. (4) The contribution of environmental factors, which independently or together with gene interaction can modulate tumor risk, is usually disregarded [36].

In the present study, we also evaluated the role of the TP53 Arg72Pro polymorphism in the overall survival of glioma patients. The evaluation did not show any statistically significant difference in overall survival among the individuals with different genotypes. When we analyzed the survival time of patients submitted to adjuvant therapy, however, we found that the patients harboring the Pro allele (Arg/Pro+Pro/Pro) had a significantly better response. This is at variance with results in other malignancies, such as head and neck, lung, breast, and ovarian cancer, for which a better outcome was seen in patients harboring the Arg allele who received adjuvant therapy [19,37-39]. A recent study showed that, under hypoxic conditions, cancer cells harboring the Pro allele had a survival disadvantage compared with cells harboring the Arg allele [40]. Notably, TP53 Arg72Pro polymorphisms might play a role in the microenvironment severe hypoxia that characterizes gliomas [41].

In conclusion, this is the first analysis of TP53 Arg72Pro polymorphism in Portuguese gliomas. We did not observe an association of TP53 Arg72Pro polymorphism with glioma risk and overall patient survival. A significant association was, however, observed in glioma patient response to adjuvant therapy. Further studies are warranted to elucidate the role of this polymorphism in combination with other genetic variants of TP53 gene and additional cancer-related genes, and to clarify the association of TP53 Arg72Pro with response of glioma patients to adjuvant therapy.

\section{Acknowledgments}

We would like to thank the Immunochemotherapy Department of S. Marcos Hospital at Braga, Portugal, and Clínica Laboratorial and Dr. Edgar Botelho Moniz at Santo Tirso, Portugal, for their helpful assistance in the management of controls.

\section{References}

[1] Kleihues P, Cavenee WK, editors. Pathology and genetics of tumours of the nervous system, 2nd ed. World Health Organization Classification of Tumours. Lyon: IARC Press, 2000.

[2] Rickert $\mathrm{CH}$, Paulus W. Epidemiology of central nervous system tumors in childhood and adolescence based on the new WHO classification. Childs Nerv Syst 2001;17:503-11.

[3] Pinheiro PS, Tyczynski JE, Bray F, Amado J, Matos E, Parkin DM. Cancer incidence and mortality in Portugal. Eur J Cancer 2003;39: 2507-20.

[4] Louis DN, Holland EC, Cairncross JG. Glioma classification: a molecular reappraisal. Am J Pathol 2001;159:779-86.

[5] Ohgaki H, Kleihues P. Genetic pathways to primary and secondary glioblastoma. Am J Pathol 2007;170:1445-53.

[6] Ohgaki H, Kleihues P. Epidemiology and etiology of gliomas. Acta Neuropathol (Berl) 2005;109:93-108. 
[7] Wrensch M, Fisher JL, Schwartzbaum JA, Bondy M, Berger M, Aldape KD. The molecular epidemiology of gliomas in adults. Neurosurg Focus 2005;19:E5.

[8] Vogelstein B, Lane D, Levine AJ. Surfing the p53 network. Nature 2000;408:307-10

[9] Lane DP. p53, guardian of the genome. Nature 1992;358:15-6.

[10] Olivier M, Eeles R, Hollstein M, Khan MA, Harris CC, Hainaut P. The IARC TP53 database: new online mutation analysis and recommendations to users. Hum Mutat 2002;19:607-14.

[11] Pietsch EC, Humbey O, Murphy ME. Polymorphisms in the p53 pathway. Oncogene 2006;25:1602-11.

[12] Thomas M, Kalita A, Labrecque S, Pim D, Banks L, Matlashewski G. Two polymorphic variants of wild-type p53 differ biochemically and biologically. Mol Cell Biol 1999;19:1092-100.

[13] Dumont P, Leu JI, Della PA III, George DL, Murphy M. The codon 72 polymorphic variants of $\mathrm{p} 53$ have markedly different apoptotic potential. Nat Genet 2003;33:357-65.

[14] Pim D, Banks L. p53 polymorphic variants at codon 72 exert different effects on cell cycle progression. Int J Cancer 2004;108:196-9.

[15] Wang YC, Chen CY, Chen SK, Chang YY, Lin P. p53 codon 72 polymorphism in Taiwanese lung cancer patients: association with lung cancer susceptibility and prognosis. Clin Cancer Res 1999;5:129-34.

[16] Suzuki K, Matsui H, Ohtake N, Nakata S, Takei T, Nakazato H, Okugi H, Koike H, Ono Y, Ito K, Kurokawa K, Yamanaka H. A p53 codon 72 polymorphism associated with prostate cancer development and progression in Japanese. J Biomed Sci 2003;10:430-5.

[17] Tiwawech D, Srivatanakul P, Karaluk A, Ishida T. The p53 codon 72 polymorphism in Thai nasopharyngeal carcinoma. Cancer Lett 2003;198:69-75.

[18] Santos AM, Sousa H, Pinto D, Portela C, Pereira D, Catarino R, Duarte I, Lopes C, Medeiros R. Linking TP53 codon 72 and P21 nt590 genotypes to the development of cervical and ovarian cancer. Eur J Cancer 2006;42:958-63.

[19] Sullivan A, Syed N, Gasco M, Bergamaschi D, Trigiante G, Attard M, Hiller L, Farrell PJ, Smith P, Lu X, Crook T. Polymorphism in wild-type p53 modulates response to chemotherapy in vitro and in vivo. Oncogene 2004;23:3328-37.

[20] Storey A, Thomas M, Kalita A, Harwood C, Gardiol D, Mantovani F, Breuer J, Leigh IM, Matlashewski G, Banks L. Role of a p53 polymorphism in the development of human papillomavirus-associated cancer. Nature 1998;393:229-34.

[21] Biros E, Kalina I, Kohut A, Bogyiova E, Salagovic J, Sulla I. Allelic and haplotype frequencies of the 553 polymorphisms in brain tumor patients. Physiol Res 2002;51:59-64.

[22] Wang LE, Bondy ML, Shen H, el Zein R, Aldape K, Cao Y, Pudavalli V, Levin VA, Yung WK, Wei Q. Polymorphisms of DNA repair genes and risk of glioma. Cancer Res 2004;64:5560-3.

[23] Parhar P, Ezer R, Shao Y, Allen JC, Miller DC, Newcomb EW. Possible association of $\mathrm{p} 53$ codon 72 polymorphism with susceptibility to adult and pediatric high-grade astrocytomas. Brain Res Mol Brain Res 2005;137:98-103.

[24] Uno M, Oba-Shinjo SM, Wakamatsu A, Huang N, Ferreira Alves VA, Rosemberg S, de Aguiar P, Leite C, Miura F, Marino RJ, Scaff M, Nagahashi-Marie SK. Association of TP53 mutation, p53 overexpression, and 553 codon 72 polymorphism with susceptibility to apoptosis in adult patients with diffuse astrocytomas. Int J Biol Markers 2006;21:50-7.

[25] Malmer BS, Feychting M, Lönn S, Lindström S, Grönberg H, Ahlbom A, Schwartzbaum J, Auvinen A, Collatz-Christensen H, Johansen C, Kiuru A, Mudie N, Salminen T, Schoemaker MJ,
Swerdlow AJ, Henriksson R. Genetic variation in p53 and ATM haplotypes and risk of glioma and meningioma. J Neurooncol 2007;82: 229-37.

[26] Costa BM, Ferreira P, Costa S, Canedo P, Oliveira P, Silva A, Pardal F, Suriano G, Machado JC, Lopes JM, Reis RM. Association between functional EGF+61 polymorphism and glioma risk. Clin Cancer Res 2007;13:2621-6.

[27] Mullenbach R, Lagoda PJ, Welter C. An efficient salt-chloroform extraction of DNA from blood and tissues. Trends Genet 1989;5:391.

[28] Wrensch M, Wiencke JK, Wiemels J, Miike R, Patoka J, Moghadassi M, McMillan A, Kelsey KT, Aldape K, Lamborn KR, Parsa AT, Sison JD, Prados MD. Serum IgE, tumor epidermal growth factor receptor expression, and inherited polymorphisms associated with glioma survival. Cancer Res 2006;66:4531-41.

[29] Wrensch M, Kelsey KT, Liu M, Miike R, Moghadassi M, Sison JD, Aldape K, McMillan A, Wiemels J, Wiencke JK. ERCC1 and ERCC2 polymorphisms and adult glioma. Neuro Oncol 2005;7:495-507.

[30] Yang P, Kollmeyer TM, Buckner K, Bamlet W, Ballman KV, Jenkins RB. Polymorphisms in GLTSCRI and ERCC2 are associated with the development of oligodendrogliomas. Cancer 2005;103: 2363-72.

[31] Bhowmick DA, Zhuang Z, Wait SD, Weil RJ. A functional polymorphism in the $E G F$ gene is found with increased frequency in glioblastoma multiforme patients and is associated with more aggressive disease. Cancer Res 2004;64:1220-3.

[32] Malmer B, Feychting M, Lönn S, Ahlbom A, Henriksson R. p53 genotypes and risk of glioma and meningioma. Cancer Epidemiol Biomarkers Prev 2005;14:2220-3.

[33] Beckman G, Birgander R, Själander A, Saha N, Holmberg PA, Kivelä A, Beckman L. Is p53 polymorphism maintained by natural selection? Hum Hered 1994;44:266-70.

[34] Själander A, Birgander R, Saha N, Beckman L, Beckman G. p53 polymorphisms and haplotypes show distinct differences between major ethnic groups. Hum Hered 1996;46:41-8.

[35] Siddique MM, Balram C, Fiszer-Maliszewska L, Aggarwal A, Tan A, Tan P, Soo KC, Sabapathy K. Evidence for selective expression of the p53 codon 72 polymorphs: implications in cancer development. Cancer Epidemiol Biomarkers Prev 2005;14:2245-52.

[36] Brennan P. Gene-environment interaction and aetiology of cancer: what does it mean and how can we measure it? Carcinogenesis 2002;23:381-7.

[37] Biros E, Kohut A, Biros I, Kalina I, Bogyiova E, Stubna J. A link between the p53 germ line polymorphisms and white blood cells apoptosis in lung cancer patients. Lung Cancer 2002;35:231-5.

[38] Xu Y, Yao LH, Ouyang T, Li JF, Wang TF, Fan ZQ, Lin BY, Lu YY, Xie YT. p53 codon 72 polymorphism predicts the pathologic response to neoadjuvant chemotherapy in patients with breast cancer. Clin Cancer Res 2005;11:7328-33.

[39] Santos AM, Sousa H, Portela C, Pereira D, Pinto D, Catarino R, Rodrigues C, Araujo AP, Lopes C, Medeiros R. TP53 and P21 polymorphisms: response to cisplatinum/paclitaxel-based chemotherapy in ovarian cancer. Biochem Biophys Res Commun 2006;340: 256-62.

[40] Sansone P, Storci G, Pandolfi S, Montanaro L, Chieco P, Bonafe M. The $\mathrm{p} 53$ codon 72 proline allele is endowed with enhanced cell-death inducing potential in cancer cells exposed to hypoxia. Br J Cancer 2007;96:1302-8.

[41] Kaur B, Khwaja FW, Severson EA, Matheny SL, Brat DJ, Van Meir EG. Hypoxia and the hypoxia-inducible-factor pathway in glioma growth and angiogenesis. Neuro Oncol 2005;7:134-53. 